\title{
Currículo e conhecimento escolar na perspectiva da educação integral
}

Cláudia Valentina Assumpção Galian*

* (Faculdade de Educação da Universidade de São Paulo, São Paulo, SP)
Resumo: Este artigo relaciona os conceitos de currículo e conhecimento escolar, conferindo centralidade ao trabalho da escola e do professor no processo de recontextualização que constitui o discurso pedagógico. Assumindo uma perspectiva de currículo em processo, procura ressaltar o significado de mudanças curriculares - tais como as que se relacionam à extensão do tempo de permanência de professores e estudantes nas escolas - para a formação escolar das novas gerações. Ressalta-se, nesse sentido, a compreensão da escola como espaço de ampliação das possibilidades de compreensão do mundo, em bases distintas das que estão disponíveis em outros espaços de socialização, e a centralidade do projeto pedagógico das escolas como eixo para a busca por ampliação do currículo, numa perspectiva de educação integral.

Palavras-chave: Currículo. Conhecimento escolar. Educação integral. 


\section{INTRODUÇÃO}

Diante das muitas iniciativas em torno da educação integral, retomadas com vigor crescente desde o início dos anos 2000, este artigo pretende chamar a atenção para a relação dessas ações com o que se espera atualmente da escola no Brasil. Mais especificamente, debruça-se sobre o debate em torno do conhecimento considerado relevante para ser disponibilizado nessas propostas de educação integral. Para isso, o texto está organizado da seguinte forma: inicialmente, serão feitos alguns apontamentos sobre diferentes concepções de currículo, a fim de delimitar o conceito com o qual se lidará na sequência; feito isto, o conceito de currículo em processo será aprofundado, com destaque para as suas dimensões e os pontos sobre os quais a extensão da jornada escolar e a ampliação da oferta de conhecimentos, na educação integral, incidem mais diretamente. Consideradas as dimensões do currículo, interessa ressaltar o processo de recontextualização do conhecimento especializado até a produção do conhecimento escolar, com destaque para o papel dos agentes envolvidos, em especial, os professores. Pretende-se, também, explorar as discussões de Michael Young em torno da distinção entre currículo e pedagogia, e, ainda, do que denomina conhecimento poderoso. Por fim, alguns elementos serão trazidos para reflexão a fim de embasar os debates sobre o significado curricular da ampliação da jornada diária de alunos e professores na escola.

\section{SOBRE CURRÍCULO}

É comum deparar com esse termo nas mais diferentes situações, nas quais ele assume significados distintos - documentos curriculares de produção federal, estadual ou municipal, planos produzidos no nível da escola, listas de conteúdos, competências, habilidades, objetivos, direitos de aprendizagem, etc. Também se fala em currículo ao se tratar do conjunto de atividades desenvolvidas na escola, diretamente envolvidas na abordagem do conhecimento ou, numa perspectiva mais abrangente, incluindo todas as experiências vividas no ambiente escolar. Como aponta Gimeno Sacristán (2000): 
Em muitos casos, fala-se de currículo referindo-se às disposições da administração regulando um determinado plano de estudos, à relação de objetivos, aos conteúdos, às habilidades, etc.; em outros, ao produto "engarrafado" em determinados materiais, como é o caso dos livros-texto; às vezes, se refere à estruturação de atividades que o professor planeja e realiza em sala de aula; às vezes, se refere às experiências do aluno na aula. Informes de avaliação de experiências ou programas também encerram um significado do currículo ou dos processos e produtos de aprendizagem considerados valiosos. O conceito currículo adota significados diversos, porque, além de ser suscetível a enfoques paradigmáticos diferentes, é utilizado para processos ou fases distintas do desenvolvimento curricular (SACRISTÁN, 2000, p. 103, grifo do autor).

Nesse sentido, também no campo teórico o currículo é objeto de diferentes abordagens, desde uma perspectiva mais técnica, que enfatiza a forma de organização do trabalho escolar e do ensino, até visões mais críticas, que sublinham o seu caráter político. Nessa linha mais crítica, enfatizase que o currículo é uma construção social que só pode ser contemplada na especificidade do contexto sócio-histórico no qual foi desenvolvida e que expressa as tensões, as lutas por significação, por representação de interesses de grupos distintos. Assim, cada forma de teorização do currículo busca explicitar e legitimar as escolhas referentes ao tipo de cidadão que se pretende formar e ao lote de conhecimentos que viabilizarão a formação desse cidadão.

Neste texto, define-se a concepção de currículo em processo como aquela que norteará a discussão que se pretende desenvolver. Mas, antes de discorrer sobre ela, é necessário afirmar o que se entende como a função social da escola: proporcionar o acesso de todos a um tipo de conhecimento que não está disponível em outro lugar, ao menos quando se pensa na grande maioria da população. Portanto, a escolha do que será ensinado está diretamente ligada ao tipo de cidadão que se pretende formar: é uma escolha política. As discussões sobre o currículo, dessa forma, não podem se restringir ao debate sobre a forma de organizar a escola e o trabalho de professores e alunos, ou mesmo sobre os métodos de ensino, sobre materiais didáticos ou sobre como avaliar a aprendizagem. Currículo é entendido como um processo que envolve muitas dimensões que, se consideradas isoladamente, não permitem a compreensão da sua complexidade.

Esse conceito de currículo como um processo, desenvolvido por Gimeno Sacristán, permite entender por que muitas das tentativas de melhorar a qualidade da educação por meio de reformas curriculares pouco se aproximam, quando o fazem, dos seus pretensiosos objetivos. Se pensarmos no currículo 
como um processo que deve ser considerado nas múltiplas articulações entre suas dimensões, fica fácil perceber que as mudanças implicam uma abordagem bem mais complexa do que normalmente se conduz nos processos de conceber e implementar novas políticas curriculares. Gimeno Sacristán (2000) assim define esse conceito:

Podemos considerar que o currículo que se realiza por meio de uma prática pedagógica

é o resultado de uma série de influências convergentes e sucessivas, coerentes ou contraditórias, adquirindo, dessa forma, a característica de ser um objeto preparado num processo complexo, que se transforma e constrói no mesmo. Por isso, exige ser analisado não como um objeto estático, mas como a expressão de um equilíbrio entre múltiplos compromissos (SACRISTÁN, 2000, p. 102).

Esse autor traça as bases para um modelo de interpretação do currículo que contempla diferentes fases ou dimensões, "como algo construído no cruzamento de influências e campos de atividade diferenciados e interrelacionados". Mas ressalta que: "Na realidade, com diferente grau e força de influência entre elementos, trata-se de um modelo cujas fases têm inter-relações recíprocas e circulares entre si” (SACRISTÁN, 2000, p. 104). Essas fases ou dimensões são: (1) o Currículo prescrito - nos documentos elaborados pelas esferas centrais para orientar o trabalho da escola; (2) o Currículo apresentado aos professores - nos materiais produzidos para uso por professores e alunos nas escolas; (3) o Currículo moldado pelos professores - a forma de organização coletiva no interior da escola, que envolve arranjos de tempos, espaços, sujeitos e saberes, e, no nível individual, os planos do professor; (4) o Currículo em ação - o conjunto de atividades desenvolvidas por professores e alunos nas salas de aula, na articulação entre esses agentes e o conhecimento a ser ensinado/aprendido; (5) o Currículo realizado - as consequências do currículo, como as aprendizagens, para os alunos, e a socialização profissional para os professores, além dos efeitos que se projetam nos âmbitos social e familiar; (6) o Currículo avaliado - os processos que explicitam o que é considerado legítimo em termos de aprendizagem, expresso em mecanismos que podem ser produzidos no âmbito interno ou no âmbito externo à escola (SACRISTÁN, 2000, p. 105-106).

$\mathrm{Na}$ concepção de currículo em processo, é a articulação entre essas dimensões, nas quais atuam diversos agentes - desde os formuladores de políticas curriculares, passando pelos autores e editores de livros didáticos e outros materiais, chegando até os professores e elaboradores de avaliações externas à escola -, que constitui o currículo real. Mais uma vez, nas palavras do autor: 
O currículo pode ser visto como um objeto que cria em torno de si campos de ação diversos, nos quais múltiplos agentes e forças se expressam em sua configuração, incidindo sobre aspectos distintos. [...] Para sua compreensão não basta ficar na configuração estática que pode apresentar num dado momento, é necessário vê-lo na construção interna que ocorre em tal processo (SACRISTÁN, 2000, p. 101).

E aí destaca-se um primeiro ponto para a reflexão ora apresentada: as propostas de ampliação do tempo na escola - concebidas no nível do currículo prescrito - incidem sobre todas essas dimensões, mas atingem uma delas mais diretamente, o currículo moldado na escola, uma vez que ampliam a jornada dos professores e alunos. Mas uma primeira dificuldade que se identifica é a relação desse aspecto com a docência. Como entender e dimensionar a importância da atuação do professor no processo de produção do conhecimento que acontece na escola? Outros questionamentos, ainda, podem ser listados: 0 que pode representar essa mudança no tempo para as demais dimensões do currículo? 0 que se deve garantir para que as potencialidades dessa alteração no tempo de permanência na escola ou em outros espaços educativos signifiquem um ganho de qualidade para a formação pretendida - considerando a função da escola, apontada anteriormente? 0 que ela pode significar para a constituição do conhecimento escolar?

\section{AS TRANSFORMAÇÕES AO LONGO DO CURRÍCULO}

Na passagem de uma dimensão do currículo para a outra, os textos produzidos sofrem transformações ligadas ao conjunto das condições que configuram cada contexto. Assim, o texto produzido, por exemplo, no nível governamental - a prescrição curricular - é deslocado do seu contexto de produção e realocado num novo contexto - das editoras de livros didáticos, por exemplo, que, com suas características distintas e seus interesses específicos, moldarão um novo texto a partir do primeiro. E assim sucessivamente em todas as dimensões antes apontadas. 0 conceito que trata desse processo de transformação dos discursos quando da sua passagem de um contexto a outro foi desenvolvido por Bernstein, que o denominou recontextualização.

A recontextualização envolve a atuação de diversos agentes situados em campos recontextualizadores - oficial e pedagógico. É a ação desses agentes que configura o que o autor denomina discurso pedagógico. 0 discurso pedagógico é um princípio que integra um discurso instrucional, ligado ao conhecimento das disciplinas específicas, num discurso regulador, atrelado à moldagem de comportamentos e atitudes segundo os valores vigentes na sociedade num dado momento: “[...] o discurso instrucional diz respeito à 
transmissão/aquisição de competências específicas e o discurso regulativo à transmissão de princípios de ordem, relação e identidade" (BERNSTEIN, 1996, p. 297).

Do ponto de vista do conhecimento que é disponibilizado nas escolas, podese pensar na recontextualização do conhecimento especializado, ligado às diversas áreas do conhecimento, em sua transformação em conhecimento escolar. Mas, sem dúvida, não se pode esquecer que à escola cabe não só a abordagem do conhecimento especializado como, também, o tratamento de uma série de normas de conduta e valores considerados legítimos para a formação do cidadão. Assim, como destaca Bernstein, o discurso ligado ao conhecimento especializado de cada área do conhecimento é inserido numa base reguladora, relacionada a essas normas e valores - esse discurso regulador, inclusive, assume maior ênfase do que o primeiro. Nesse sentido, vamos aprofundar a análise da atuação dos professores no complexo processo de constituição do conhecimento escolar.

\section{O PAPEL DO PROFESSOR NA PRODUÇÃO DO CONHECIMENTO ESCOLAR}

Inicialmente, destaca-se o já amplamente reconhecido papel desempenhado pelos professores no acompanhamento e no apoio aos alunos para que consigam identificar pontos de contato entre o que já sabem sobre determinado fenômeno e o conhecimento novo, que aos poucos lhes vai sendo apresentado. Nesse processo, não se trata de simplificar o conhecimento especializado para garantir a compreensão por parte dos alunos, mas de um processo muito mais complexo e que, portanto, implica sérias discussões sobre a formação desse professor. Sobre a atuação desse agente, Gimeno Sacristán (2000) destaca, enfatizando o caráter político do papel atribuído socialmente ao professor:

Quem, a não ser o professor, pode moldar o currículo em função das necessidades pessoais e sociais dentro de um contexto cultural? A figura do professor como mero desenvolvedor do currículo é contrária a sua própria função educativa. O currículo pode exigir o domínio de determinadas habilidades relacionadas com a escrita, por exemplo, mas só o professor pode escolher os textos mais adequados para despertar o interesse pela leitura com um grupo de alunos (SACRISTÁN, 2000, p. 168).

Cortesão e Stoer (2003) afirmam que esse espaço para a recontextualização por parte dos professores é crucial para que se possa fazer a gestão da diversidade na escola. Lidando com os conceitos de Bernstein, esses autores tratam, por exemplo, dos saberes que o professor deve acionar 
para selecionar conteúdos e formas de abordagem visando a aprendizagem de um determinado grupo de alunos, sempre marcado pela diversidade. Nesse sentido, ressaltam que, ao fazer essas seleções, os professores precisam acionar dois tipos de conhecimentos: (1) aqueles que levantam a partir do reconhecimento das especificidades do grupo - que envolvem, portanto, um mapeamento de múltiplas características dos alunos e da comunidade na qual vivem, de natureza sociológica, psicológica, cognitiva, emocional, etc. e (2) conhecimentos envolvidos na recriação de conteúdos e na concepção de uma metodologia adequada aos contextos e aos tipos de alunos (CORTESÃO; STOER, 2003, p. 194). Este, para os autores, representa um cruzamento fecundo e original do conhecimento especializado com os contributos das teorias do currículo, das didáticas das diferentes disciplinas, etc. Trata-se, assim, de duas transformações que são conduzidas no processo de recontextualização que se desenvolve na atuação do professor: do conhecimento especializado num novo texto, com base nos conhecimentos prévios dos alunos, e no processo pedagógico, segundo o que definem as ciências da educação. Constitui-se, portanto, sob a batuta do professor e com base no conhecimento socioantropológico de sua turma, um espaço de tradução cultural. Para os autores:

\footnotetext{
[...] a pedagogia de ensino e a sua preocupação com a transmissão do conhecimento - em que a centralidade dos conhecimentos a veicular determina o processo pedagógico - tem de se articular com a pedagogia de aprendizagem, em que as características da criança e do jovem assumem centralidade no processo de ensino-aprendizagem. Se essa articulação não for realizada [...], os conhecimentos educativos e socioculturais produzidos sobre os alunos não serão contemplados no processo pedagógico, tendendo o processo educativo, como consequência, a reduzir-se à performance transmissora do professor e à performance reprodutora (do saber) dos alunos (CORTESÃO; STOER, 2003, p. 197, grifos dos autores).
}

Essa atuação do professor, para além das marcas psicológicas e técnicas que porta, é expressão, também, de uma escolha política assumida num dado contexto. Ela traz em si a forma de uma sociedade responder ao questionamento sobre "se se deve intervir ou não, onde e em que medida. Quer dizer, não se trata de ver como os professores veem e transferem 0 currículo para a prática, mas se têm o direito e a obrigação de contribuir com seus próprios significados (GRUNDY, 1987, p. 69)” (SACRISTÁN, 2000, p. 165).

É fácil constatar que, para que este importante espaço de recontextualização, de transformação dos textos de forma coerente com as características dos grupos de alunos e das escolas seja garantido e valorizado do ponto de vista da elaboração de políticas educacionais, é exigida a atuação em muitas frentes: 
(1) na busca por uma sólida formação inicial e continuada dos professores da escola básica - o que implica profunda discussão acerca do que conferiria tal solidez -, (2) na valorização do professor, expressa inclusive, mas não unicamente, na remuneração desses agentes, passando, também, pelo respeito e pela consideração do trabalho desenvolvido por eles e pelas escolas nas proposições de políticas educacionais, (3) no apoio governamental, em especial das instâncias locais, no que se refere ao acompanhamento das escolas e à articulação do seu trabalho com o de outras instituições sociais.

Vale neste ponto retomar o que foi até aqui desenvolvido: inicialmente, afirmou-se que a função da escola é proporcionar acesso a um conhecimento não disponível, para a maioria da população, em outros contextos além do escolar. Esse conhecimento, que envolve elementos do conhecimento especializado e, também, um lote de saberes ligados aos valores, normas, procedimentos que norteiam a vida numa sociedade em determinado contexto, deverá ser apresentado a um público muito diversificado. Defendese que, na produção do conhecimento escolar, o papel do professor é central, deve ser valorizado e que as escolas devem ser igualmente apoiadas em suas iniciativas e assistidas pelas secretarias de educação no sentido de buscar a coerência e a viabilidade das suas ações em relação ao plano formativo expresso nos seus projetos pedagógicos, que, sem dúvida, se articulam com as definições curriculares mais amplas assumidas na esfera federal. Mas, claro, essa articulação terá especificidades e assim deve ser. Quanto mais detalhadas as definições/orientações centrais, menor é o espaço para esses ajustes locais, absolutamente indispensáveis quando se pensa nas características muito diferenciadas nas quais escolas, professores e alunos desenvolvem seus papéis.

\section{QUAL CONHECIMENTO, ENTÃO?}

Pensando na definição do que deve compor o currículo e na articulação entre ele e a docência, cabe trazer à discussão as posições defendidas por Michael Young em sua produção acadêmica mais recente. Esse autor vem defendendo que se pense no que define como conhecimento poderoso, que constitui uma ideia bastante instigante. O conhecimento poderoso é exatamente aquele ao qual todos devem ter acesso porque é o que traz instrumentos para a compreensão do mundo no qual se vive, em outras bases, diferentes daquelas que se constroem nas relações familiares ou nos grupos mais amplos nos quais se circula. Para ele, esse conhecimento é diferente do conhecimento do senso comum e é o mais adequado para compor o currículo 
escolar, não porque seja mais valioso em si, mas porque é mais importante para a consecução da função específica da escola - a ampliação dos horizontes de compreensão da prática social, o desenvolvimento intelectual das novas gerações. Em entrevista concedida à revista Educação e Pesquisa (GALIAN; LOUZANO, 2014), Young afirma que “um currículo que incorpore o conhecimento poderoso é um currículo que se concentra no conhecimento ao qual os jovens não têm acesso em casa. É distinto da experiência pessoal deles e, essencialmente, desafia essa experiência" (GALIAN; LOUZANO, 2014, p. 1118). Para ele, inclusive, um importante tipo de pesquisa a ser realizado no campo do currículo:

\footnotetext{
[...] é o que incide sobre o processo de recontextualização, ou seja, sobre a maneira como o conhecimento especializado, produzido pelos pesquisadores de diferentes campos, é retirado do contexto onde foi desenvolvido e inserido noutro contexto, que tem como principal objetivo a transmissão e o acesso a esse conhecimento. E, também, sobre como esse conhecimento é selecionado para compor o currículo. Precisamos saber muito mais sobre esse processo do que sabemos hoje (GALIAN; LOUZANO, 2014, p. 1117).
}

Young defende que o acesso ao conhecimento poderoso é para todos, o que supõe a ideia de um núcleo comum para o currículo, coerente com o plano formativo que se assumiu num determinado contexto. Mas, nessa perspectiva, o que deveria constar nesse currículo comum? Basicamente, as definições sobre o que deve ser disponibilizado, ou seja, uma seleção do que se define como os melhores instrumentos desenvolvidos pelos campos do conhecimento, ou o mais longe que se chegou em cada área na explicação do mundo. Para ele, esse núcleo comum:

\footnotetext{
[...] deve consistir num conjunto de diretrizes sensiveis aos diferentes campos do conhecimento, mas suficientemente abertas para permitir que as escolas as interpretem nos diferentes contextos. [...] A equipe da escola precisa ter um conhecimento suficiente de teoria do currículo para poder interpretar na sua escola esse currículo comum, de forma que haja algum tipo de diálogo entre o nacional e o local. E isso é perfeitamente factível! É uma coisa sempre tratada como um problema, mas, mesmo que você tenha nascido e crescido no meio da Amazônia, você tem o direito democrático ao conhecimento poderoso. Essas crianças precisam ter algum conhecimento de coisas como a matemática [por exemplo], onde quer que estejam (GALIAN; LOUZANO, 2014, p. 1121).
}

E aqui, um ponto polêmico do pensamento de Michael Young: na concepção dessa seleção do que comporá o currículo, na sua dimensão prescrita, não entra o conhecimento do aluno ou o seu interesse. 0 que conta é o conhecimento especializado, ligado às disciplinas escolares.

Será isso a expressão de um retrocesso em relação a tudo o que já se avançou na consideração da relevância das especificidades culturais dos 
aprendizes na escola? A defesa de um currículo que nega a experiência dos grupos sociais e assume uma natureza de erudição, a fim de calar outras vozes detentoras de pouco ou nenhum poder na configuração social? Não é o que o autor admite. Para ele, o conhecimento do aluno, bem como os seus interesses, são absolutamente imprescindiveis para o trabalho do professor. Este é o material que informa ao professor o ponto de partida na abordagem do conhecimento das disciplinas, o que pode fazer sentido para seus alunos, e que embasa suas escolhas relativas ao método de ensino, à sequência na qual será apresentado, o tempo que sua abordagem demandará. Em outras palavras, essa é uma questão ligada à didática - ou, como surge na tradução de seus textos, à pedagogia, embora o próprio autor já tenha assumido que em português faria mais sentido falar em didática. Em seus termos, ele afirma, na entrevista antes referida, que:

[...] a distinção entre currículo e didática é importante por duas razões. Uma delas é que, se não houver a distinção, corre-se o risco de colocar no currículo muitas coisas relacionadas

à experiência dos alunos, coisas que não deveriam estar lá. A experiência dos alunos é essencial para o professor, porque é por aí que ele deve começar, com aquilo que os alunos

trazem para a sala de aula; esse é o principal recurso do professor. Mas o trabalho do professor é sempre levá-los desse ponto inicial para algum outro lugar (GALIAN; LOUZANO, 2014, p. 1121).

Em síntese, Young diferencia currículo e pedagogia, ou, didática, embora destaque que essa é uma distinção que não cabe para o professor em sua atuação, mas para os elaboradores de políticas. Explicando: currículo referese à seleção de conhecimento considerado legítimo e cujo acesso deve ser garantido a todos; didática refere-se ao trabalho do professor, à sua atuação naquele espaço, antes mencionado, de tradução cultural. Mas, claro, nas ações do professor, currículo e didática se misturam constantemente:

\section{[...] a distinção entre currículo e didática é teórica, não prática. Porque, na prática, se você é um professor, universitário ou de ensino básico, as duas coisas caminham juntas. Você não fica o tempo todo fazendo a distinção, "isto é currículo, isto é didática". Mas, se você está elaborando currículos - seja em nível individual, local ou nacional -, então a distinção é importante, porque o currículo define o que se ensina, que direção você vai tomar, enquanto a didática trata do como (GALIAN; LOUZANO, 2014, p.1122, grifos das autoras).}

O autor salienta que o currículo deve ser compreendido como as definições amplas sobre qual é o conhecimento que deve ser disponibilizado nas escolas e não as orientações estritas sobre como devem atuar os professores. Este é o espaço do saber específico do professor e suas escolhas deverão se desenvolver na relação com seus alunos, nas condições reais que encontra nas escolas. Não cabe aos elaboradores de políticas, portanto, avançar sobre 
esse espaço de atuação do professor, porque, na tentativa de controlar o trabalho docente para buscar atingir a qualidade da educação, restringese a margem para a articulação entre diferentes saberes na composição do conhecimento escolar - papel que cabe a esse agente.

\section{A EDUCAÇÃO INTEGRAL ENTENDIDA COMO MUDANÇA CURRICULAR}

Encaminhando o final dessa reflexão, destaca-se o potencial das políticas de ampliação da jornada de alunos e professores nas escolas - forma majoritariamente assumida nas iniciativas em torno da educação integral desenvolvidas nos últimos anos. Retoma-se, para isso, a afirmação da função específica da escola, qual seja, a ampliação dos recursos para a compreensão e a análise da prática social, do mundo em que se vive. Nesse sentido, mais tempo na escola deve servir a esse propósito, ao desenvolvimento intelectual de crianças e jovens. Não pode ser entendido como recurso para protegê-los das ruas ou para proteger as ruas deles. Em coerência com essa posição em relação à escola, entende-se que a extensão do tempo de permanência na escola ou em outros espaços educativos a ela vinculados, entendida como recurso para a consecução de uma educação integral, precisa ser assumida como ocupação do tempo em atividades vinculadas ao projeto pedagógico da escola, ao projeto formativo assumido pelo coletivo da instituição e à função específica dessa instituição na sociedade.

Por esse motivo, a sequência para a tomada de decisões sobre o que se fará com o tempo adicional na escola deveria ser: antes de tudo, a ampla discussão que culmina no projeto pedagógico de cada instituição - o texto que expressa qual é o plano que se traça para o desenvolvimento de crianças e jovens; depois, as escolhas que compõem o currículo que deverá garantir a formação afirmada no projeto pedagógico e que tomará por base as definições centrais relativas aos grandes temas a serem abordados na escola, sem delimitações muito rígidas em relação ao tempo (por exemplo, sem especificações de expectativas de aprendizagem/direitos de aprendizagem e desenvolvimento a serem cumpridas num período estreito de tempo), as características do alunado e da comunidade, as tradições da escola - o que vem sendo feito, como vem sendo feito, o que faz sentido para aquele grupo -, os recursos locais que podem ser acessados, na parceria com outras instituições sociais e com o apoio das instâncias governamentais. É central, portanto, o projeto pedagógico da escola; ele é que norteia a reestruturação curricular exigida pela ampliação da jornada escolar na direção da educação integral. 
A partir dos anos 2000, essa ideia de ampliação da jornada escolar vem ganhando força como um caminho para a conquista da qualidade da educação. Essas iniciativas são justificadas de duas maneiras principais, segundo Coelho (2012): como uma busca por melhoria na qualidade do ensino, por meio de uma formação mais completa, e como recurso para a proteção à criança em situação de vulnerabilidade social (COELHO, 2012, p. 81). Nesse sentido, a autora identifica duas formas de abordar a questão, explicadas por dois termos distintos: escola de tempo integral e aluno em tempo integral. No primeiro caso, a ampliação da jornada estaria ligada à função que se atribui socialmente à escola - serviria à busca por garantir a consecução dessa função. No segundo caso, a extensão da jornada estaria ligada não à função da escola, mas à formação do aluno. Se tomarmos a definição de educação integral como aquela que contempla o ser humano em suas múltiplas dimensões, a ideia de aluno em tempo integral aparentemente é mais coerente com essa perspectiva. Mas a autora faz um alerta que merece atenção: muitas vezes, essa concepção de aluno em tempo integral traz em seu bojo um viés de assistencialismo, de busca por cobrir lacunas formativas de muitas naturezas, especialmente quando se trata dos alunos mais pobres e desfavorecidos, secundarizando ou mesmo perdendo de vista a função da escola, de criar condições para o acesso a conhecimentos historicamente produzidos e legitimados, que permitam a tomada de distância em relação à prática social na qual estão inseridos esses alunos. Esta é uma possibilidade, ainda que não tenha de ser necessariamente assim.

Concordando com Coelho, outra pesquisadora da temática, Ana Maria Cavaliere, defende que isso pode ser evitado se a articulação das experiências oferecidas pela educação integral se mantiver ligada aos projetos pedagógicos das escolas, de modo a que se possa propiciar mudanças no caráter da experiência escolar, aprofundando determinados traços da vida nesta instituição. $E$, sobre esses traços, ela lembra que a escola vai além da instrução, uma vez que é também responsável pela socialização de crianças e jovens, em bases distintas daquelas que caracterizam a família ou o grupo de convívio mais próximo: "Toda e qualquer escola sempre atua, ou pretende atuar, para além da instrução escolar. Um grau de responsabilidade socializadora, principalmente para as crianças pequenas, é inerente à vida escolar" (CAVALIERE, 2007, p. 1022).

Assim, juntando as posições apresentadas neste texto, sobre currículo e educação integral, sublinho o caráter fluido do processo que constitui o currículo, sobre o qual incidem muitos sujeitos, com distintos interesses, 
constituindo escolhas provisórias que devem responder às condições específicas e às metas formativas assumidas em cada escola. Essas condições e essas escolhas devem compor o eixo estruturador do currículo ampliado, vivificado, multidimensional da educação integral. Este seria o melhor currículo, uma vez que se apoiaria nos planos formativos mais amplos definidos para o país, mas sempre buscaria sentido na realidade concreta a que estão submetidos escolas, professores e alunos.

Outro desafio inegável consiste em romper com práticas cristalizadas nas escolas, que frequentemente atuam no sentido de dificultar mudanças nas formas de uso dos tempos e espaços, bem como nas relações entre os sujeitos. Uma escola que se abre para outras experiências e saberes, sem abrir mão dos conhecimentos escolares, mas lançando mão deles como instrumentos para a compreensão do mundo em bases distintas das que provêm da experiência imediata, precisa ousar nessas formas de organização. Outras lógicas invadirão a escola e dizer que a centralidade está no projeto pedagógico não significa dizer que suas tradições não devam ser crivadas de questionamentos, de modo a manterem-se aquelas que de fato contribuem para a formação que se pretende desenvolver.

\section{CONSIDERAÇÕES FINAIS}

A ampliação do tempo de permanência de professores e estudantes na escola, tal como se expressa em muitas iniciativas assumidas como sendo expressão da busca por uma educação integral, é defendida aqui como mais tempo para o cumprimento da função específica da escola. Em outras palavras, o tempo a mais é entendido como potencialmente favorável para o processo de tradução cultural que se dá no desenvolvimento do trabalho de professores e alunos, que culmina na constituição do conhecimento escolar. Mais tempo é vislumbrado como elemento potencialmente favorecedor de condições para se cuidar da gestão da diversidade na escola.

Em outros textos, já se discutia se a questão do currículo tem sido tratada com a centralidade necessária nos diferentes trabalhos que vêm analisando as experiências de educação integral em tempo integral (GALIAN; SAMPAIO, 2014; SAMPAIO; GALIAN, 2015). Nele, buscou-se refletir sobre as implicações dessas propostas sobre o currículo da escola, considerado em sua complexidade, como se procurou desenvolver anteriormente no presente artigo. Isso significa entendê-lo não apenas como os documentos que orientam o trabalho da escola, mas como a somatória dos desdobramentos desses documentos, tais 
como: os materiais didáticos produzidos para uso por professores e alunos, as formas de organização de tempos, espaços e sujeitos na escola, as escolhas de conteúdo e forma realizadas pelos professores em suas aulas, aquilo que se define como o que vai expressar se houve a aprendizagem, nas avaliações externas a que são submetidos os estudantes. Nessa direção, considerouse ser preciso buscar e assumir respostas para algumas questões, tais como: Para quem se dirige essas medidas de extensão da jornada escolar? Qual a formação que se almeja? Qual currículo responderia a essa formação pretendida?

Em relação à pergunta “Para quem se dirige a extensão da jornada?”, sublinhouse a ideia de formação integral para todas as crianças e jovens, avançando para além da indicação de iniciativas que focalizam a população mais pobre, socialmente mais vulnerável. Tal formação foi entendida como diretamente ligada à consolidação de uma relação com o conhecimento que garanta a aprendizagem dos conteúdos necessários à compreensão da prática social na qual se está inserido, e mesmo a possibilidade da sua transformação. Assim, como se afirmou no referido texto:

\section{[...] crianças e jovens oriundos de camadas sociais mais favorecidas continuam tendo o acesso historicamente garantido a este trabalho específico da escola, com a devida qualidade, sem secundarizar o cuidado que todos devem receber - assim, a prioridade na ampliação do tempo não pode ser apenas uma medida de proteção social para a população mais pobre; tem que ser para garantir o cumprimento da função específica da escola, também - e primordialmente - para essa camada da população (SAMPAIO; GALIAN, 2015, p. 26).}

Com relação à segunda questão, “Qual a formação que se pretende desenvolver?”, a posição defendida constitui uma:

[...] opção clara por dirigir a extensão do tempo para o enfrentamento das fragilidades da formação oferecida nas escolas, de modo especial no que se refere ao trabalho com o conhecimento; não se pode desperdiçar esta medida, se a escolha é pela consolidação de uma escola de boa qualidade, que garanta aprendizagem efetiva e verdadeira formação para todos

(SAMPAIO; GALIAN, 2015, p. 26).

Focalizar o currículo nas reflexões sobre educação integral implica questionar a escola no seu modo de funcionar e atuar, nas características e demandas do trabalho pedagógico, nas dificuldades e possibilidades que se abrem diante da extensão do tempo de permanência na escola. Isso "exige entender o currículo na relação com todo o trabalho escolar, como elemento determinado e determinante, com centralidade na organização da prática pedagógica" (SAMPAIO; GALIAN, 2015, p. 26).

Assim, o que se defende é que as ações curriculares que aconteçam em outros 
espaços, para além da escola, devem responder às demandas apontadas pela comunidade escolar e devem derivar de prioridades registradas nos projetos político-pedagógicos das escolas. A ampliação do tempo no qual o aluno fica sob a responsabilidade da escola precisa significar a busca por desenvolver atividades que partem de necessidades e demandas da escola, segundo as escolhas expressas em seu projeto pedagógico, tendo em vista a aprendizagem e demais aspectos da formação dos estudantes, e que também podem ser oferecidas por outras instituições. Mas de nada adianta oferecer uma profusão de atividades e experiências para ocupar o tempo das crianças, descaracterizando o trabalho escolar, o seu projeto educativo, que se baseia na relação de conhecimento:

Tempos mais largos e flexíveis pedem ampliação e multiplicidade de espaços para a oferta de atividades diversificadas, que permitam, inclusive, proximidade efetiva com a natureza e a prática social, além da exploração de várias linguagens e saberes de diferentes áreas. Espera-se a oferta de muitas atividades, recursos múltiplos, abertura para muitas situações novas de vivência cultural, mas sem dispersão, sem perder de vista o processo de conhecimento, o ensino e a aprendizagem daquilo que é mais necessário ao cidadão que se está formando na escola (SAMPAIO; GALIAN, 2015, p. 29).

Essa posição se assenta no entendimento de que o projeto da escola não separa conhecimento e educação: conhecimento que instrumentaliza para a reflexão e permite uma participação crítica na vida em sociedade:

Simplesmente acolher, ocupar o tempo e distrair os estudantes é altamente conservador e reprodutor da desigualdade social, pois reforça a transmissão de atitudes conformistas, formando pessoas sem crítica, bem tranquilas, preparadas para manter seu lugar social e seu papel de subordinados. Defender o trabalho efetivo de conhecimento, ao contrário, faz parte da defesa da escola como conquista da população e espaço potencialmente democrático e emancipador de formação para seus sujeitos (SAMPAIO; GALIAN, 2015, p. 37).

Uma alteração no tempo escolar - como a que acontece na maioria das ações que afirmam buscar uma educação integral - traz implicações para as outras dimensões do currículo. Nessa busca por novas configurações de práticas e discursos, a escola e os professores precisam ser auxiliados e respeitados. Enfatiza-se, portanto, que os tempos expandidos não podem servir apenas para acréscimo de atividades em contraturno, sob o único argumento da necessidade de oferecer o que não está disponível no contexto em que vivem os alunos. Contar com mais um turno de permanência nas escolas - ou em atividades a elas ligadas - pode produzir um atendimento desencontrado e que não resulte em incremento da formação. Mas, se se mantém o foco na aprendizagem dos alunos, esse tempo a mais pode ser utilizado para enfrentar a lógica dos tempos recortados que comumente organiza o ensino, com base 
na suposição de que a aprendizagem de todos os alunos se dá da mesma forma e no mesmo ritmo. Essa suposição faz com que se deixem de lado muitos alunos que, a despeito de permanecerem na escola, não acessam o que nela se poderia disponibilizar - crianças e jovens desconhecidos em suas características e necessidades e privados do acesso ao conhecimento escolar. A ampliação da jornada deve estar a favor de práticas que contemplem essa diversidade presente nos grupos de alunos e que favoreçam a aprendizagem e o desenvolvimento de todos.

Finaliza-se este artigo com uma afirmação: não é tarefa fácil discutir o currículo. Não é fácil e resulta sempre em acordos provisórios. Mas essa provisoriedade não deve ser motivo para se evitar assumir tais acordos - é preciso fazer escolhas e tais escolhas serão mais favoráveis a determinados grupos e obscurecerão ou calarão outras vozes, já que sempre são feitas sob uma determinada configuração de poder. Atentos a essas marcas, devemos manter a consciência, também, em relação à provisoriedade dessas escolhas, o que é fundamental e nos obriga a assumir uma postura de constante vigilância e de disposição para o debate. 


\section{Curriculum and Knowledge in the Perspective of Integral Education}

Abstract: This article relates the concepts of curriculum and school knowledge, conferring centrality on schools' and teachers' work in the process of recontextualizing what constitutes the pedagogical discourse. By assuming a perspective of in-progress curriculum, the study seeks to highlight the meaning of curricular changes - such as the ones related to increasing teachers' and students hours in school - to the schooling of new generations. Therefore, we highlight a view of the school as a space for widening the possibilities of understanding the world on different foundations than those available in other contexts of socialization, as well as the centrality of schools' pedagogical project as a guideline to broaden the curriculum in an integral education perspective.

Keywords: Curriculum. School knowledge. Integral education. 


\section{Currículo y conocimiento escolar en la perspectiva de la educación integral}

Resumen: Este artículo relaciona los conceptos de currículo y conocimiento escolar, dando centralidad al trabajo de la escuela y del profesor en el proceso de recontextualización que constituye el discurso pedagógico. Asumiendo una perspectiva de currículo en proceso, busca resaltar el significado de cambios curriculares -tales como los relacionados con la extensión del tiempo de permanencia de profesores y estudiantes en las escuelas- para la formación escolar de las nuevas generaciones. Cabe destacar, en este sentido, la comprensión de la escuela como espacio de ampliación de las posibilidades de comprensión del mundo, en bases distintas a las que están disponibles en otros espacios de socialización, y la centralidad del proyecto pedagógico de las escuelas como eje para la búsqueda de ampliación del currículo, en una perspectiva de educación integral.

Palabras clave: Currículo. Conocimiento escolar. Educación integral. 


\section{REFERÊNCIAS}

BERNSTEIN, Basil. A estruturação do discurso pedagógico: classes, códigos e controle. Petrópolis: Vozes, 1996.

CAVALIERE, Ana Maria. Tempo de escola e qualidade na educação pública. Educação \& Sociedade, v. 28, n. 100, p. 1015-1035, 2007.

COELHO, Lígia M. M. Alunos no ensino fundamental, ampliação da jornada escolar e educação integral. Educar em Revista, Curitiba, n. 45, p. 73-89, jul.set. 2012.

CORTESÃO, Luiza; STOER, Stephen R. A interface de educação intercultural e a gestão de diversidade na sala de aula. In: GARCIA, Regina L.; MOREIRA, Antônio F. B. (Org.). Currículo na contemporaneidade. Incertezas e desafios. São Paulo: Cortez, 2003. p. 189-207.

GALIAN, Cláudia V. A.; SAMPAIO, Maria das Mercês F. Conhecimento escolar na escola de tempo integral. In: SILVA, Roberto Rafael Dias da (Org.). Currículo e docência nas políticas de ampliação da jornada escolar. 1. ed. Porto Alegre: Evangraf, 2014. v. 1, p. 11-28.

; LOUZANO, Paula B. J. Michael Young e o campo do currículo: da ênfase no "conhecimento dos poderosos" à defesa do "conhecimento poderoso”. Educação e Pesquisa, v. 40, n. 4, p. 1109-1124, out.-dez. 2014.

SACRISTÁN, Jose Gimeno. 0 currículo. Uma reflexão sobre a prática. Porto Alegre: Artmed, 2000.

SAMPAIO, Maria das Mercês F.; GALIAN, Cláudia V. A. Escola, tempo e currículo. In: BITTENCOURT, Jane; THIESEN, Juares S.; MOHR, Adriana (Org.). Projetos formativos em educação integral. Investigações plurais. Florianópolis: NUP/ CED/UFSC, 2015. p. 13-42. 
Sobre a autora

Cláudia Valentina Assumpção Galian é doutora em Educação pela Pontifícia Universidade Católica de São Paulo e professora da Faculdade de Educação da Universidade de São Paulo.

claudiavalentina@usp.br

Recebido em: junho de 2016

Aprovado em: julho de 2016 